\title{
BIPHASIC ACTION OF RETINOIDS ON GONADOTROPIN RECEPTOR INDUCTION IN RAT GRANULOSA CELLS IN VITRO
}

\author{
P. Bagavandoss and A.R. Midgley Jr \\ Department of Physiology \\ and \\ Consortium for Research in \\ Developmental and Reproductive Biology \\ The University of Michigan \\ Ann Arbor, MI 48109
}

(Recelved in final form September 16, 1988)

\section{Summary}

Vitamin A (retinol) has been held to be uniquely essential for normal vision (1) and reproduction (2), all other functions being served by its metabolite retinoic acid (3-6). The inability of retinoic acid to maintain adequate serum progesterone $(7-10)$ is implicated as the cause of fetal resorption $(8,9)$. The availability of lipoproteins is a major limiting factor in progesterone production (12-15) and the ovarian expression of lipoprotein receptors is dependent on the action of luteinizing hormone (LH) (16). Therefore, we investigated the effects of retinol and retinoic acid on $\mathrm{LH}$ receptor induction by ovarian cells in an attempt to determine the basis for the reported differences in the gonadal action of these two retinoids. Our results indicate that retinoic acid $\left(10^{-10} \mathrm{M}\right)$ and retinol $\left(10^{-8} \mathrm{M}\right)$ each synergistically enhance the ability of follicle stimulating hormone (FSH) to induce LH-receptors and to stimulate the formation of cyclic adenosine 3',5'-monophosphate (cAMP) and progesterone. However, at higher concentrations, both retinoids inhibited these effects of FSH. For every measured effect, retinoic acid was more potent than retinol. Since retinol is metabolized to retinoic acid in other tissues, these results suggest that retinoic acid may be the mediator of the action of retinol on the ovary and that retinol's unique effect on reproduction needs to investigated further.

Vitamin A has long been known to be essential for cell differentiation, growth, reproduction, and vision. Vitamin A-deficiency leads to degeneration of testicular germ cells in male rats, fetal resorption in pregnant rats, and blindness in both sexes $(1,2)$. In 1960, Dowling and Wald demonstrated that the maintenance of normal vision by vitamin $A$ cannot be replaced by vitamin $A$ acid and commented then, "it appears from these experiments that the only function vitamin A may perform directly in the rat is to supply the prosthetic group of its visual pigments. All other functions - growth, general tissue maintenance - are served equally well by vitamin A acid" (1). This claim was supported by additional experimental evidence $(3,4,5,6)$. However, in 1964 it was demonstrated that in addition to vision, the maintenance of normal reproductive function in both male and female rats required retinol (2). Subsequent studies confirmed this and showed that serum and ovarian progesterone concentrations were decreased in retinol-deficient rats, regardless of supplementation with retinoic acid $(7,8,9,10)$. 
In these rats, decreased activity of steroidogenic enzymes has been implicated as the cause of decreased progesterone production $(8,10)$. These results were contrary to our finding of no differences in the ability of retinoic acid and retinol to increase progesterone production by rat luteal cells in vitro (11). Recent studies on ovarian steroidogenesis indicate that the optimal production of progesterone is limited by the availability of lipoproteins to this organ (12-15) and LH increases luteal cell surface lipoprotein receptors, which function to transfer plasma cholesterol into cells (16). Therefore, we hypothesized that retinoids may affect the ovarian production of progesterone by influencing the induction of $\mathrm{LH}$ receptors in differentiating granulosa cells.

\section{Reagents and hormones}

\section{Methods}

Dulbecco's Modified Eagle medium (DMEM) and Ham's medium F12 (F12) were purchased from Grand Island Biological Co., Grand Island, NY. Trypsin, soybean trypsin inhibitor (SBTI), bovine pancreas deoxyribonuclease (DNase) I, gentamicin sulfate, phenylmethylsulfonylfluoride (PMSF), N-2hydroxyethylpiperazine-N'-2-ethanesulfonic acid (HEPES), $N$ tris[hydroxymethyl]methyl-2-aminoethane sulfonic acid (TES), N,N-bis[2hydroxyethyl]-2-aminoethane sulfonic acid (BES), retinol, retinoic acid, diethylstilbestrol (DES), and the fluorescent dye bisbenzimid (Hoechst 33258) were from Sigma Chemical Co., St. Louis, MO. Ethylenediaminetetraacetic acid (EDTA) was from Mallinckrodt, Paris, KY. Dimethyl sulfoxide (DMSO) was from Aldrich Chemical Co., Milwaukee, Wi. Medical-grade Silastic tubing (0.078" id and 0.125" od) was purchased from Dow Corning, Midland, MI. Polypropylene tubes were purchased from Sarstedt, W. Germany.

Human chorionic gonadotropin (hCG, $2700 \mathrm{IU} / \mathrm{mg}$ ) was from Hypo Labs, Coinsins, Switzerland. Highly purified hCG (CR-119; $11600 \mathrm{IU} / \mathrm{mg}$ ) used for iodination was obtained from the Center for Population Research of the NICHHD, NIH. The ovine follicle stimulating hormone (NIAMDD-oFSH-14, 9 X NIH FSH$\mathrm{S} 1$ ), used in cultures was from the National Pituitary agency and was prepared by DR. A.F. Parlow.

\section{Animal model and in vitro $L H$ receptor induction}

Immature female rats were implanted with $3.0 \mathrm{~cm}$ Silastic capsules containing diethylstilbestrol (DES) on day 21 of age. The ovaries were removed 4 days later, granulosa cells expressed, and the cells cultured in serum-free 1:1 Dulbecco's Modified Eagle's Medium (DMEM) and Ham's nutrient F-12 (F12) as described previously (17). Two hundred and fifty thousand cells in $600 \mu \mathrm{l}$ were cultured in polypropylene tubes for 3 days at $37 \mathrm{C}$ in an atmosphere of $95 \%$ air-5\% $\mathrm{CO}_{2}$ with high humidity. The following reagents were included in the incubation as indicated below: FSH-NIAMDD oFSH-14 (9 X NIH-FSH-S1), Retinoic acid and retinol (Sigma). The retinoids were dissolved in dimethyl sulfoxide (DMSO). The final concentration of DMSO in medium was less than $0.1 \%$ which did not affect cellular viability or other parameters that were measured.

\section{$L H / h C G$ receptor assay}

The assay was performed as described previously (17). Briefly, at the end of cell culture the tubes were centrifuged at $2500 \mathrm{rpm}$ for 15 minutes and the medium was transferred to another set of tubes for determination of cAMP and progesterone. The cell pellets were resuspended in $1 \mathrm{ml}$ of phosphate buffered saline-0.1\%gelatin (gel-PBS) containing $3 \%$ bovine serum albumin (BSA). The tubes were centrifuged again, and the supernatants were removed. The pellets were resuspended in $200 \mu \mathrm{l}$ of gel-PBS containing about $1.5 \mathrm{ng}(250,000 \mathrm{cpm})$ of iodinated hCG (18) (s.a. $42 \mu \mathrm{Ci} / \mu \mathrm{g}$ hCG). Nonspecific binding was determined in 
the presence of excess $(1.5 \mu \mathrm{g})$ unlabeled hCG. The tubes were incubated for 3 hours at $25 \mathrm{C}$. The incubation was terminated by the addition of $3 \mathrm{ml}$ of cold gelPBS followed by centrifugation at $30,000 \mathrm{xg}$ for 15 minutes. The supernatant was aspirated, resuspended again in $3 \mathrm{ml}$ gel-PBS, centrifuged, the supernatant aspirated and the pellets were counted.

Fluorometric DNA assay was performed as described by Labarca (19) with minor modifications (20). Briefly, the tissue pellets were resuspended in $3.9 \mathrm{ml}$ of $0.05 \mathrm{M}$ phosphate buffer containing $2.0 \mathrm{M} \mathrm{NaCl}(\mathrm{pH} \mathrm{7.4)}$ and mixed with $100 \mu \mathrm{l}$ of fluorochrome $(4 \mu \mathrm{g} / \mathrm{ml}$ in distilled water). The fluorochrome was also added to calf thymus DNA standards $(4 \mu \mathrm{g} / \mathrm{ml})$. The samples and DNA standard were incubated in dark at $25 \mathrm{C}$ for 2 hours. They were then read at an excitation and emission wavelengths of 350 and 456 nanometers respectively, in a Perkin-Elmer LS-5 spectrophotometer.

\section{Progesterone and cyclic AMP RIA}

The media from cultures were boiled for 10 minutes to destroy the phosphodiesterase activity and were assayed for cAMP and progesterone contents as described previously $(21,22)$.

\section{Statistical analyses}

Analysis of variance (ANOVA) was performed on both raw and logtransformed data to account for heteroschedasticity of the variance. If this analysis showed significance $(p<0.05$ or less), the data were subsequently analyzed by Bonferroni T test (23) to isolate particular treatment effect. Although the experiments have been repeated at least three times, because of the intrinsic variabilities in primary cultures between experiments, results from representative experiments are presented.

\section{Results}

Neither retinoic acid nor retinol were able to induce $\mathrm{LH}$ receptors in the absence of FSH (Table 1). As expected, treatment with FSH induced LH receptors and stimulated the accumulation of cAMP and progesterone (Table 1). Retinoic acid inhibited this induction in a dose-dependent manner. Inhibition of receptor induction by retinoic acid was always associated with corresponding decrease in cAMP and progesterone concentrations (Table 1). Retinol, on the other hand, significantly enhanced the ability of FSH to induce LH receptor (Table 1). Since saturating concentrations of iodinated hCG were used in these binding studies, the increase in receptor binding reflects an actual increase in the number of binding sites. This enhanced receptor-induction was associated with increased accumulation of both cAMP and progesterone (Table 1 ).

Retinoic acid at concentrations between $10^{-6} \mathrm{M}$ and $10^{-8} \mathrm{M}$ inhibited the induction of $\mathrm{LH}$ receptor by $\mathrm{FSH}$; at $10^{-9} \mathrm{M}$ retinoic acid had no effect on the ability of FSH to induce $\mathrm{LH}$ receptor; at $10^{-10} \mathrm{M}$ retinoic acid actually enhanced $\mathrm{FSH}$ induction of LH receptor (Figs. 1 and 2). This biphasic action of retinoic acid was associated with parallel changes in the concentrations of cAMP and progesterone (Fig. 1). When the abilities of retinoic acid and retinol to modulate FSH actions were compared, retinoic acid was found to be much more potent. Thus, retinoic acid at $10^{-6} \mathrm{M}, 10^{-7} \mathrm{M}$ and $10^{-8} \mathrm{M}$ inhibited the FSH induction of $\mathrm{LH}$ receptor by $96 \%$, $66 \%$, and $13 \%$ respectively (Fig. 2), In contrast, retinol failed to inhibit FSH induction of $\mathrm{LH}$ receptor at concentrations ranging from $10^{-7} \mathrm{M}$ to $10^{-10} \mathrm{M}$, and only at $10^{-6} \mathrm{M}$ was significant inhibition (60\%) observed (Fig. 2). 
TABLE I

Effect of Retinoids on FSH-dependent LH/hCG Receptor Induction, cAMP and Progesterone Accumulation by Rat Granulosa Cells

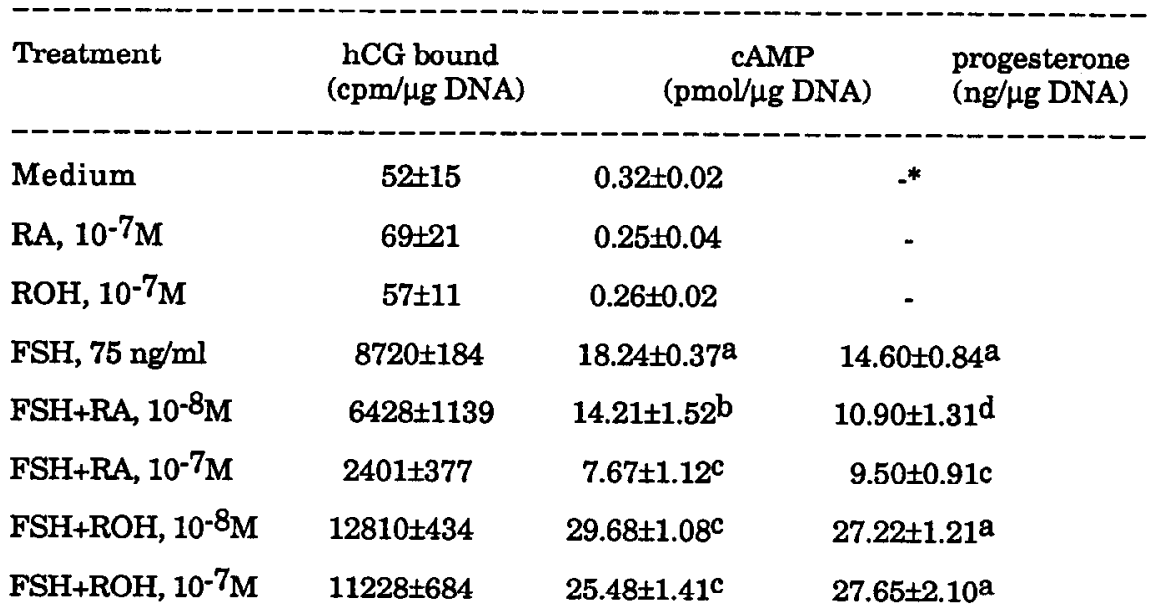

Effect of retinoids on FSH-induced LH/hCG receptor induction, cAMP, and progesterone accumulation in rat granulosa cells. Granulosa cells were cultured in serum-free medium as described in Materials and Methods with FSH, retinoic acid (RA), and retinol (ROH) as indicated. At $72 \mathrm{~h}$, the cultures were terminated and hCG binding to cells and progesterone and cAMP accumulation in media were measured. Each value represents the mean of 7 replicates \pm SEM. Values for FSH are compared with Medium and the values for FSH+retinoids are compared with FSH-values. *minimally detectable, a $p<0.0001, b p<0.05, c p<0.001, d p<.02$.

\section{Discussion}

Our results indicate that retinoic acid and retinol each modulate FSHdependent receptor induction, most likely by effecting changes in concentration of cAMP (Table 1, Fig. 1). Further the capacity of these retinoids to modify the FSHdependent receptor induction appears to depend on the sensitivity of these cells to FSH. As previously shown, in response to FSH, receptor induction varies between experiments by as much as three-fold (17). In this study also, FSH-induced receptor induction varies between experiments (Figs. 1,2, Table 1). Consequently, the response to retinoids also appears to be affected. Thus, when FSH-induced receptors were low, marked response to retinol (Table 1) and retinoic acid (Fig. 1) was observed. However, when the response to FSH was high, only moderate response to retinoids was observed (Fig. 2). The actual modulator of FSH-induced functions, however, may be retinoic acid, not retinol. Retinoic acid is more potent than retinol and retinol is known to be metabolized to retinoic acid within the cells. A similar relationship has been demonstrated with F9 embryonal carcinoma cells (24). Retinol-induced differentiation of these cells can be mimicked by much lower concentrations of retinoic acid. Thus, it was shown that in induction of differentiation of these cells retinoic acid was one hundred and seventyfive times more potent than retinol. Further, maximum differentiation was accomplished within 48 hours in the presence of retinoic acid whereas 72 hours was required in the presence of retinol suggesting the lag time for 

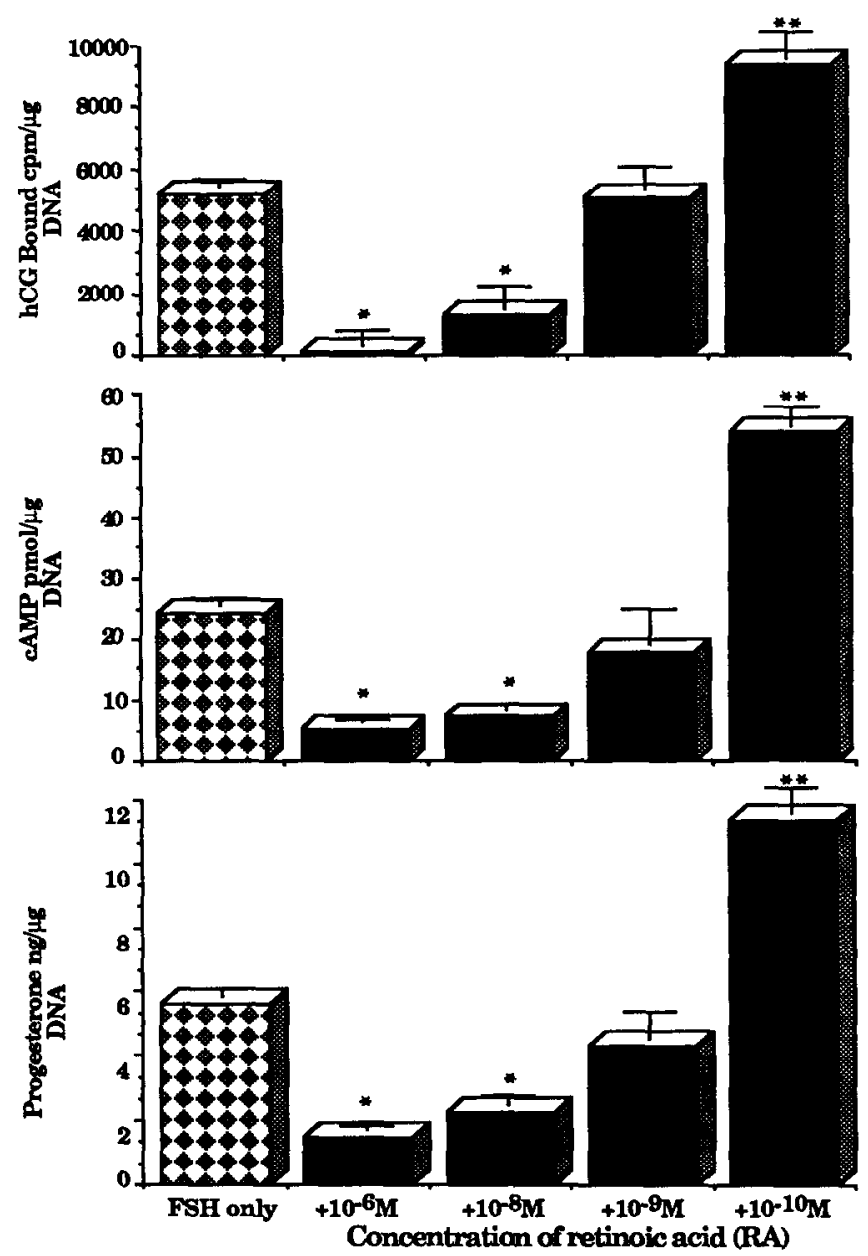

FIG. 1

Biphasic action of retinoic acid on FSH-induced $\mathrm{LH} / \mathrm{hCG}$ receptor induction and cAMP accumulation in rat granulosa cells. Granulosa cells were cultured in serum-free medium as described in Materials and Methods with FSH alone or FSH plus retinoic acid as indicated. At $72 \mathrm{~h}, \mathrm{hCG}$ binding and cAMP accumulation were measured. Each value represents the mean of three replicates \pm SEM. Values for FSH+RA are compared with FSHvalues. ${ }^{*} \mathrm{p}<0.005, * *$ $\mathrm{p}<0.01$.

conversion of retinol to retinoic acid. That retinoic acid is the actual mediator of this differentiation was further demonstrated by inhibiting the metabolism of retinoic acid (24).

If the results reported here are applicable to conditions in vivo and to the effects of retinoids on testicular function, a number of prior reports will need to be reinterpreted. Thus, the reported inability of retinoic acid to restore ovarian function in vitamin A-deficient rats may have resulted from use of this metabolite in amounts sufficiently high to inhibit induction of LH-receptor. Administration of high amounts of retinoic acid would be expected to lead to reduced concentrations of gonadal cAMP (25), testosterone (25), and progesterone $(7,8,9,10)$ observed in several studies. This interpretation would also account for the observation of insensitivity to gonadotropins induced by high dosages of retinoic acid (7) and the apparently normal LH-stimulated testosterone response of testes of rats given low amounts of retinoic acid (26). In this context, it is interesting to note that the biphasic action of retinoic acid is not restricted to the ovary. Recently it has been shown that retinoic acid enhanced and depressed the development of bone anlagen in embryonic mouse limbs at low and high concentrations respectively (27). Further, although vitamin $A$ is an essential vitamin, hypervitaminosis A causes many disorders $(28,29)$. 


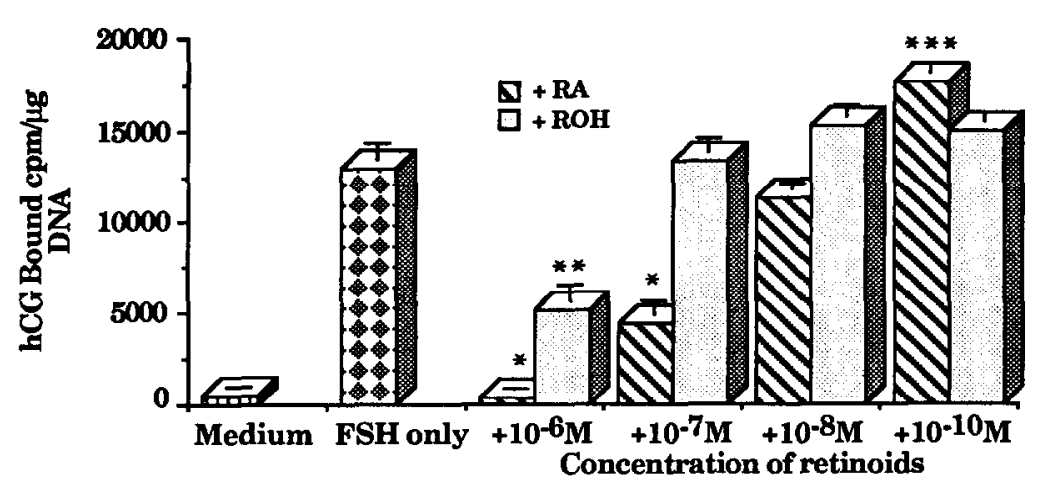

FIG. 2

\begin{abstract}
Relative potencies of retinol ( $\mathrm{ROH}$ ) and retinoic acid (RA). Granulosa cells were cultured in serum-free medium as described in Materials and Methods with FSH and retinoids as indicated. At $72 \mathrm{~h}$, hCG binding was determined. Each value represents the mean of 5 replicates \pm SEM. Both retinoic acid and retinol had a biphasic effect on FSH-induced hCG receptor induction. However, in each case, retinoic acid was more potent than retinol. Values for FSH are compared with Medium and the values for FSH+retinoids are compared with FSH-values. ${ }^{*} p<0.0001,{ }^{* *} p<0.005,{ }^{* * *}$ $\mathrm{p}<0.05$.
\end{abstract}

The in vive results obtained from retinoic acid supplemented vitamin Adeficient rats should be interpreted with great caution. Although intracellular receptors for both retinol and retinoic acid are present in a variety of tissues including the ovary $(11,30)$, unlike retinol which is present in high concentration in plasma $(\sim 400 \mathrm{ng} / \mathrm{ml})(31)$, the circulating concentration of retinoic acid is low $(\sim 3 \mathrm{ng} / \mathrm{ml})(31)$. Furthermore, the circulating retinol is bound to a specific transport protein (32) and delivery of retinol to target tissues is facilitated by a cell surface receptor mediated mechanism (33). Therefore, under physiological conditions the amount of retinol available to tissues is regulated by the number of cell surface receptors for the transport protein. Accordingly, the amount of intracellular retinoic acid formed from retinol is also restricted. Since dietary supplementation of retinoic acid in vitamin A-deficient animals bypasses this highly regulated physiological delivery of this vitamin to tissues and since retinoic acid has biphasic effects on granulosa cell function, the earlier in vivo results are difficult to interpret. Thus, although the supplemented retinoic acid may be adequate for apparent normal growth of animals, the physiological concentrations of retinoic acid required by different tissues may vary considerably.

What then is the function of retinol in reproduction? Both ovary and uterus have receptors for retinoic acid and retinol (30). Since retinoic acid appears to support the ovarian production of progesterone, what is the function of cellular retinol binding protein in the ovary? Is binding of retinol to its receptor prerequisite for its subsequent conversion to retinoic acid? Does retinol possess an endocrine unrelated function which is vital for the maintenance of pregnancy? This possibility has been raised by earlier investigators $(34,35)$. Since the resorption of fetus appears to be initiated by the necrotic changes in the placenta (2), is it likely that retinol may have direct effects on placental physiology rather than on the ovary? Clearly, additional studies along these lines as well as the availability of nonmetabolizable analogs of retinol will throw light on the role of retinol in reproduction. 
The mechanism by which retinoids modulate hormone function is not clear. In other systems it has been shown that retinoic acid not only transcriptionally regulates gene expression (36) but also affects cellular growth and differentiation by modulating intercellular junctional communications (37-39). Since granulosa cells possess large number of gap junctions in vivo (40) and since the dispersed granulosa cells are able to rapidly reestablish gap junctions in vitro (41), the effects on receptor induction and steroidogenesis may also involve modulation of gap junctions by retinoids or the underlying events that control their expression.

In conclusion, the results reported here, obtained in vitro, indicate that the retinoids, retinol and retinoic acid, can exert biphasic effects on ovarian function with retinoic acid possessing greater activity at all concentrations. The results suggest that while retinol acts to support normal ovarian function, the effect may actually be mediated by its metabolite retinoic acid. If the biphasic effects of retinoids are applicable in vivo, low concentrations of retinoids can serve to correct the deficiency while high concentrations act to inhibit LH-receptorinduction and subsequent LH-dependent events.

\section{References}

1. J. E. DOWLING and G. WALD, Proc. Natl. Acad. Sci. 46: 587- 608 (1960).

2. J. N. THOMPSON, J. Mc. C. HOWELL and G. A. J. PITT, Proc. Roy. Soc. B159: 510-535 (1964).

3. P. L. HARRIS, Vitam. and Horm. 18: $341-370$ (1960).

4. J. N. THOMPSON and G. A. J. PITT, Nature. 188: 672-673 (1960).

5. J. D. WOOD, Canad. J. Biochem. Physiol. 40: 529-536 (1962).

6. H. B. FELL, J.T. DINGLE and M. WEBB, Biochem. J. 83: 63-69 (1962).

7. H. S. JUNEJA, N. R. MODUGAL and J. GANGULY, N. R. Biochem. J. 111: 97-105 (1969).

8. J. GANGULY, G.S. POPE, S.Y. THOMPSON, J. TOOTHILL, J.D. EDWARDSWEBB and H.B. WAYNFORTH, Biochem. J. 122: 235-239 (1971).

9. G.S. POPE, S.Y. THOMPSON, J. TOOTHILL, J.D. EDWARDS-WEBB and H.B. WAYNFORTH, Biochem J. 123: 669-670 (1971).

10. M. JAYARAM, S.K. MURTHY and J. GANGULY, Biochem. J. 136: 221-223 (1973).

11. P. BAGAVANDOSS and A. R. MIDGLEY JR, Endocrinology 121: 420-428 (1987).

12. M.H. CHRISTIE, J.F. STRAUSS III and G.L. FLICKINGER, Endocrinology 105: $92-98$ (1979).

13. L.A. SCHULER, M.E. TOAFF, and J.F. STRAUSS III, Endocrinology 108: 1476-1486 (1981).

14. S. AZHAR and K. M. J. MENON, J. Biol. Chem. 256: 6548-6555 (1981).

15. B.C. BRUOT, W.G. WIEST, and D.C. COLLINS, Endocrinology 110: 1572-1578 (1982).

16. J. HWANG and K. M. J. MENON, J. Biol. Chem. 258: 8020-8027 (1983).

17. M. M. SANDERS, and A. R. MIDGLEY JR, Endocrinology 111: 614-623 (1982).

18. F. C. GREENWOOD, W. M. HUNTER and J. S. GLOVER, Biochem. J. 89: 114-123 (1963).

19. C. LABARCA, and K. PAIGEN, Analyt. Biochem. 102: 344-352 (1980).

20. S. L. FIELDS and T. R. VALIQUETT, Biol. Reprod. 30: Abst\# 264 (1984).

21. J. S. RICHARDS, J. A. JONASSEN, A. I. ROLFES, K. KERSEY and L. E. REICHERT JR, Endocrinology 104: 765-773 (1979).

22. D. J. ELBAUM, E. M. BENDER, J. M. BROWN and P. L. KEYES, Biol. Reprod. 13: 541-545 (1975). 
23. J.R. MILLER, Simultaneous Statistical Inference, pp. 67-68, McGrawHill, New York, (1966).

24. J. B. WILLIAMS and J. L. NAPOLI, Proc. Natl. Acad. Sci. 82: 4658-4662 (1985).

25. K. K. STEINBERG and D. S. SGOUTAS, Proc. Soc. Exp. Biol. Med. 167: $110-116$ (1981).

26. D. R. APPLING and F. CHYTIL, Endocrinology 108: 2120-2123 (1981).

27. T.E. KWASIGROCH, J.F. VANNOY, J.K. CHURCH and R.G. SKALKO, In Vitro Cell. and Devel. Biol. 22: 150-156 (1986).

28. E.D. KAY, Teratology 35: 105-117 (1987).

29. A.K. SILVERMAN, C.N. ELLIS and J.J. VOORHEES, J. Am. Acad. Dermatol. 16: 1027-1039 (1987).

30. D. E. ONG and F. CHYTIL, J. Biol. Chem. 257: 13385-13389 (1982).

31. M. E. CULLUM and M. H. Zile, J. Biol. Chem. 260: 10590-10596 (1985).

32. M. KANAI, A. RAZ and D. S. GOODMAN, J. Clin. Invest. 47: 2025-2044 (1968).

33. M. K. Bhat and H. R. CAMA, Biochim. Biophys. Acta 587: 273-281 (1979).

34. W. A. COWARD, J. Mc. C. HOWELL, G. A. J. PITT and J.N. THOMPSON, J. Reprod. Fert. 12: 309-317 (1966).

35. E. Q. CALAUSTRO and I. J. LICHTON, J. Nutr. 95: 517-525 (1968).

36. S.-Y. WANG, G. J. LAROSA and L. J. GUDAS, Devel. Biol. 107: 75-86 (1985).

37. P. P. MEHTA, J. S. BERTRAM and W. R. Loewenstein, Cell 44: 187-196 (1986).

38. J. D. PITTS, R. R. BURK and J. P. MURPHY, Cell Biol. Intl. Reports Supplement A5, p. 45 (1981).

39. L. WALDER and R. LUTZELSCHWAB, Exp. Cell Res. 152: 66-76 (1984).

40. D .F. ALBERTINI and E. ANDERSON, Anat. Rec. 181: 171-194 (1975).

41. K. L. CAMPBELL and D. F. ALBERTINI, Tissue and Cell 13: 651668 (1981). 